\title{
HEIDEGGER Y SLOTERDIJK: LA PROVOCACIÓN DE LA TÉCNICA, EL CLAROSCURO DE LA VERDAD Y LA DOMESTICACIÓN DEL SER (MÁS ALLÁ DE LA MATRIZ BUCÓLICA DE LA PASTORAL HEIDEGGERIANA)
}

\section{Adolfo Vásquez Rocca ${ }^{1}$}

Universidad de Valparaiso

Universidad Complutense de Madrid

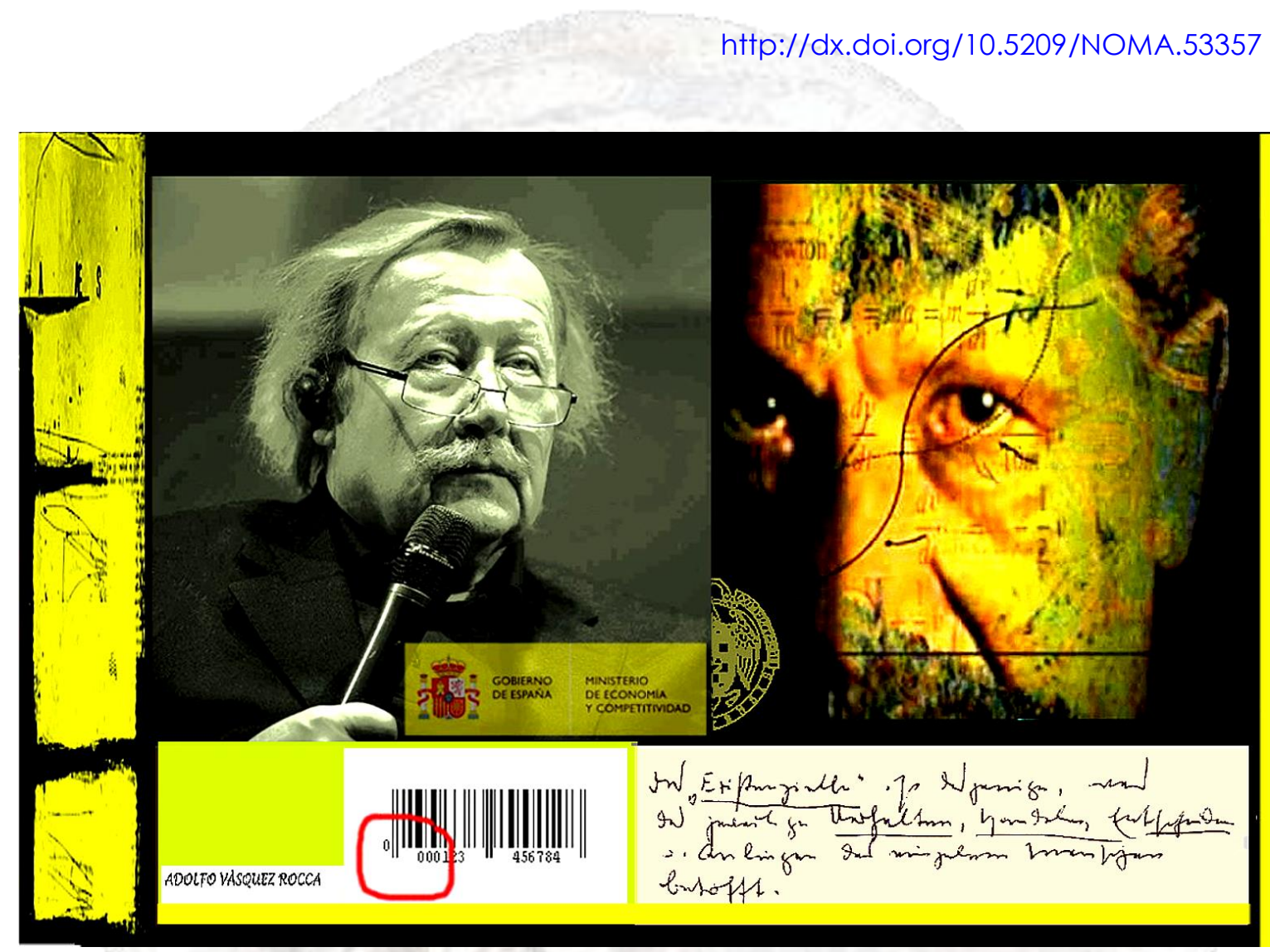

Resumen.- Para Sloterdijk, Heidegger es el último metafísico de la vieja Europa, porque su pensamiento permanece totalmente vinculado al paradigma de un mundo en crecimiento tal y como es experimentado por un campesino. La concepción de un mundo en crecimiento comporta las ideas de productividad y progreso. Pero, ¿̇e qué producto y progreso se trata? El producto en cuestión es aquí, ante todo, el hombre mismo, y el progreso, su cometido de guardar el Ser y corresponderle como su pastor. En este Artículo se trata, de modo especial, las discusiones éticas que corren en dirección paralela a la técnica, acudiendo para esto a la revisión de la concepción heideggeriana de los "pastores del ser", cuya "candidez" humanística y moralizante, es - por decir lo mínimo- anacrónica. Adentrándose en estas formulaciones heideggerianas, Sloterdijk también interrogará por ¿̇uiénes son los pastores del Ser? ¿Quiénes son los vigilantes, y qué significa ser vecino de esa extraña abstracción (el Ser)? La amonestación fundamental de Heidegger es la de mantener una atenta y diligente disposición a la llamada del Ser, a la escucha. El artículo concluye con el examen de la matriz bucólica campesina, como pastoral cristiana, propia de la

\footnotetext{
1 https://www.ucm.es/emui/adolfo-vasquez-rocca
} 
lectura tradicional de Heidegger, frente a lo cual Sloterdijk vislumbra los peligros del "capitalismo cárnico contemporáneo", que se cierne sobre el hombre a la luz del nuevo diseño civilizatorio. Así los pastores son ahora, no sólo carnívoros, sino grandes ganaderos que no sólo guardan sus rebaños, sino que también los vigilan y dirigen su reproducción a gran escala.

Palabras claves: Técnica, verdad, casa, claro, ser, pastor, tiempo, errancia, mundo, habitar, construir, pensar.

\title{
Heidegger and Sloterdijk: The provocation of the technique, the chiaroscuro of truth and domestication of Being (beyond the bucolic pastoral Heidegger matrix).
}

\begin{abstract}
For Sloterdijk, Heidegger is the last metaphysician of old Europe, because his thought remains entirely linked to the paradigm of a growing world as it is experienced by a farmer. The conception of a growing world behaves ideas of productivity and progress. But, what product and progress is it? The product in question is here, above all, the man himself, and progress, its mission to save the Being and reciprocate as their pastor. This article is a special way, the ethical arguments that run parallel to the technical direction, going for this to revision of Heidegger's conception of the "shepherds of being" whose humanistic and moralizing "naivete" is - mínimo- say the anachronism. Getting into these formulations Heidegger, Sloterdijk also interrogated by who are the shepherds of Being? Who are the watchers, and what it means to be a resident of that strange abstraction (Self)? The fundamental admonition Heidegger is to maintain a careful and diligent available to the call of Being, listening. The article concludes with an examination of the bucolic matrix peasant, as Christian pastoral, typical of the traditional reading of Heidegger, against which Sloterdijk sees the dangers of "contemporary meat capitalism" that hangs over the man in the light of the new civilizational design. So pastors are now not only carnivores, but large farmers who not only keep their herds, but also monitor and run large-scale reproduction.
\end{abstract}

Keywords: Technical, truth, house, of course, be, pastor, time, wandering, world, live, build, think.

\section{1.- El claroscuro de la verdad y las sombras del nacionalsocialismo.}

Al ocuparse de la cuestión de la verdad Sloterdijk se inspirará en la teoría heideggeriana de la apertura de la existencia humana al mundo. En su constitución fundamental el hombre es abierto a lo que hay allí donde está y el espacio mundano es claro y deja ver lo que allí se encuentra. La apertura y el claro son partes principales de la idea de verdad de Heidegger.

Las meditaciones de Heidegger para determinar de nuevo 'la esencia de la verdad', son reflexiones que toman su punto de partida en la palabra griega alethéia, lo no oculto, lo no escondido, para ver en ella una indicación del paso de lo oculto al lado diurno de los entes". 2

2 SLOTERDIJK, Peter, Esferas III, Sirvela, Madrid, 2004, p. 218. 
Esta interpretación de la verdad como desocultamiento le asigna un lugar en el orden fenoménico. La verdad en su sentido primordial es una posibilidad inseparable del hombre: ella le ocurre dinámicamente, sucede en el tiempo, es un ir y venir entre lo escondido y lo manifiesto. ${ }^{3}$ De la humanidad capaz de verdad se dirá, entonces, que es a la vez extática sin dejar de ser íntima. Esta doble condición de poder estar fuera de sí y adentro consigo es lo que hace posible que el hombre tenga mundo, una exclusividad que no comparte con nadie.

Sloterdijk critica a Heidegger su concepto de mundo y particularmente el modo de concebir la entrada del hombre en él. Según Heidegger somos arrojados en el mundo, cosa ominosa que tiene el acento de un un oscuro castigo; de este modo el mundo moderno, hogar largamente preparado por la historia de lo monstruoso violento y arbitrario (das Ungeheure), es el lugar en el que luchan los gigantes poderes impersonales ligados a la técnica apocalíptica.

La verdad, pues, no se descubre inocuamente y sin batalla, sino sólo después de triunfar batallando contra sus antecesoras, que la enmascaran y se le oponen. "En el universo del conocimiento moderno predominan los bastidores, los suelos dobles, los panoramas, las imágenes engañosas, los gestos torcidos, los sentimientos secretos, los motivos ocultos los cuerpos envueltos". 4 La historia de la verdad es concebida por Heidegger, a partir del estado de cosas del año 1946. como la quemazón de un hilo conceptual combustible extendido desde Atenas a Hiroshima. $5^{5}$ El cual, como puntualiza Sloterdijk, sigue hasta los laboratorios de ingeniería genética (Gentechnik) actuales.

Sloterdijk no repara en objetar a Heidegger el haberse dejado arrastrar por la marea de la política, comprometiéndose con el nacionalsocialismo -cuestión tratada exhaustivamente por una copiosa literatura previa-, criticándole además por sus preferencias localistas, provincianas y nacionalistas, todas las cuales le habrían impreso un talante anacrónico no sólo a su personalidad sino fundamentalmente a sus doctrinas y a sus obras. ${ }^{6}$

El Nacionalsocialismo constituyó para Heidegger un proyecto cultural en el que parecía estar en juego el resurgimiento de Alemania, de allí que la adhesión de Heidegger a dicho movimiento deba ser entendida como una posición político metafísica, un pretendido "nacionalsocialismo privado", estrechamente ligada a su imaginario

\footnotetext{
3 Ibídem., p. 428.

4 SLOTERDIJK, Peter, Crítica de la razón cínica, Siruela, Madrid, 2008, II, p. 604

5 CORDUA, Carla, Sloterdijk y Heidegger; La recepción filosófica, Santiago, Ediciones Universidad Diego Portales, 2008, p. 113.

6 VÁSQUEZ ROCCA, Adolfo "Sloterdijk y Heidegger. La recepción filosófica. Recensión y estudio crítico", En UNIVERSITAS @ C Revista de Filosofía, Derecho y Política, $N^{\circ}$ 10, 2009, pp. 151-159. Universidad Carlos III de Madrid. http://universitas.idhbc.es/n10/10-08.pdf
} 
filoagrario, a su apego a la tierra y su rechazo de la racionalidad técnica. La posición de Heidegger, sin embargo, olvida los componentes esenciales del movimiento y la ideología nazi, movimiento que fue siempre una mezcla incongruente de tradicionalismo e innovación, de ruralismo bucólico e hipermodernismo, de mistificación de los valores vernáculos de la tierra, y tecnificación avanzada para la guerra más demoledora.

\section{2.- El pensamiento filoagrario de Heidegger.}

La afirmación de Sloterdijk según la cual Heidegger es el último cerebro de la era agraria sienta la tesis directriz del presente artículo. ${ }^{7}$ Para Sloterdijk, Heidegger es el último metafísico de la vieja Europa, porque su pensamiento permanece totalmente vinculado al paradigma de un mundo en crecimiento tal y como es experimentado por un campesino. 8 La concepción de un mundo en crecimiento comporta las ideas de productividad y progreso. Pero, ¿̇de qué producto y progreso se trata? El producto en cuestión es aquí, ante todo, el hombre mismo, y el progreso, su cometido de guardar el Ser y corresponderle como su pastor. Lo que hay en juego en todo esto es la expresión de un problema antiquísimo, a saber, el de la cría y domesticación del hombre por el hombre; un problema en el que han estado involucrados, por referirse sólo al gremio, todos los filósofos, y que podría denominarse como la disputa por la antropogénesis, esto es, la lucha encarnizada por obtener un derecho procreador y tutorial sobre el hombre, una gigantomakhia peri tou ántropou. 9 Es en razón del intento heideggereano de dilatar el imaginario de la era agraria del mundo que se puede barruntar el porqué de la aversión de Heidegger hacia la democracia, el capitalismo, el socialismo, el humanismo, la técnica y el industrialismo de la era hoy en curso, era que al fin se ha hecho cuestión de la crisis de la paternidad y del principio genealógico de la especie o de la criatura hombre.

Heidegger, haciendo gala de la aguda perspicacia del reaccionario, advierte la sociedad de la democracia liberal y capitalista como el fin definitivo de la comunidad en torno a la tierra. En este sentido la afirmación de Sloterdijk según la cual "Heidegger es el último cerebro de la era agraria", trae consigo la concepción de la política clásica según la cual los hombres eran obras de hombres gestados en el seno

7 VÁSQUEZ ROCCA, Adolfo, Peter Sloterdijk; Esferas, helada cósmica y políticas de climatización, Colección Novatores, $N^{\circ} 28$, Editorial de la Institución Alfons el Magnànim (IAM), Valencia, España, 2008. Cap. VI "Sloterdijk y Heidegger; Metáfora de la navegación, hiperpolítica y crítica del imaginario filoagrario". pp. 99 - 112.

$8 \quad$ SLOTERDIJK, Peter, (1994) En el mismo barco; ensayo sobre la hiperpolítica, Ed., cit., p. 50

9 Paráfrasis del dictum de El Sofista de Platón según la cual la filosofía ha sido una "lucha de gigantes en torno a la ousía". 
de la comunidad, a la vez que unidos a la tierra por un cordón umbilical llamado tradición. En este proceso histórico de conservación del hombre por el hombre, la metafórica agraria concebía a cada nueva generación de hombres como el producto del orden y rotación inmemorial de siembras y cosechas. 10

Heidegger, en este texto, vuelve la mirada a un idílico estado preindustrial, mirada que se corresponde con la sensibilidad neorromántica de los poetas láricos como Trakl o Teillier, quienes están constantemente intentando regresar a la aldea-al pueblo natal- como muestra de rechazo (velado o inconsciente) de la ciudad moderna, creando un mundo imaginario en el cual declaran verdaderamente habitar, y en donde se da el verdadero arraigo, la vuelta al mundo de la infancia y la confianza en la memoria y la leyenda. La vivienda y el hogar, son elementos decisivos que permiten al hombre desarrollar un sentido de su propio yo, en tanto que perteneciente a un lugar determinado.

En la obra de Heidegger se esta constantemente buscando retornar al origen, ya sea por el camino hermenéutico, ya por las señales de ruta dejadas en el devenir etimológico de las palabras o mediante la reconstrucción de sentidos primigenios a través de ejemplos tomados de una vida de aldea, en la cual se puede percibir una gran nostalgia, la misma que él -Heidegger- reconoce en la poesía de Trakl. Una nostalgia por aquel mundo del orden inmemorial de las aldeas y de los campos, en donde siempre se produce la misma segura rotación de las siembras y las cosechas, de sepultación y resurrección, tan similares a la gestación de los dioses propios de la poesía de Hölderlin. En las obras de Heidegger vemos las cosas dotadas de vida, las cosas vividas, el trato con las cosas cotidianas, con las cosas admitidas en nuestra confianza, esto es lo que Heidegger entenderá como el ser de lo útil. 11

En 1933, Heidegger se afilia al partido nazi y acepta el rectorado de la Universidad de Friburgo. Rechaza una cátedra en Berlín, alegando que para el pensador, como para el campesino, el terruño es "su universo de trabajo". Su hostilidad hacia los espacios urbanos nace de su identificación con el paisaje de la Selva Negra, donde la técnica aún no ha destruido el misterio de las fuerzas elementales. Sus reiteradas exhortaciones a unir "las fuerzas incontaminadas del alma germánica" con el "querer" del Estado nacionalsocialista, no impiden que se niegue a expulsar de la universidad a dos colegas opuestos al régimen y que,

10 VÁSQUEZ ROCCA, Adolfo, "Heidegger y Sloterdijk: La política como plástica del ser, nacionalsocialismo privado y crítica del imaginario filoagrario" En NÓMADAS, Revista Crítica de Ciencias Sociales y Jurídicas - Universidad Complutense de Madrid, $\begin{array}{llllll}N^{\circ} & 21 & \text { I } & \text { Enero-Junio.2009 } & \text { (I) }\end{array}$ http://www.ucm.es/info/nomadas/21/avrocca.pdf

11 RIVERA, Jorge Eduardo, Heidegger y Zubiri, Ed. Universitaria, Chile, 2001, p. 63. 
incluso, organice un seminario con uno de ellos, el jurista Eric Wolf. Antes de que venza su nombramiento, Heidegger dimite como rector.

La meditación sobre la técnica ocupa los años siguientes. Durante 1938, organiza un seminario sobre El trabajador, de Ernst Jünger, interrumpido por una prohibición oficial del régimen nacionalsocialista. Heidegger describe al trabajador como la apoteosis de la voluntad de poder, que realiza su proyecto de dominio mediante la movilización total y la técnica planetaria. Es la misma tesis de La época de la imagen del mundo, importante conferencia donde se afirma que en el mundo actual "el hombre pasa a ser el centro de referencia del ente como tal". El imperialismo planetario de la técnica puede manifestarse como nazismo, comunismo o capitalismo, pero en todos los casos prevalece una subjetividad que convierte lo real en una relación de objetos consumibles. Después de la guerra, las autoridades francesas le prohíben seguir ejerciendo la docencia.

Ahora bien, para entender en profundidad la adhesión de Heidegger al nacionalsocialismo, atendiendo a lo previamente expuesto, y sin embargo no incurrir en simplificaciones banales, podemos recordar las palabras de la Introducción a la metafísica ${ }^{12}$, basada en una lección que dictara Heidegger el año 35 en la Universidad de Friburgo, y que se publicara el año 53, donde contrasta la "verdad y grandeza" del movimiento nacionalsocialista con la miseria de su aparición histórica: "Lo que hoy se ofrece por todas partes como filosofía del nacionalsocialismo -pero que no tiene absolutamente nada que ver con la interior verdad y grandeza de este movimiento (a saber, el contacto entre la técnica globalmente determinada y el hombre moderno)- hace su pesca en esas turbias aguas de 'valores' $y$ 'totalidades"'. Heidegger sostuvo haber adherido a una suerte de "nacionalsocialismo privado"13, de acuerdo al cual él estaba convencido de que a Alemania le correspondía la misión de superar el "oscurecimiento mundial", suscitado principalmente por el dominio de las grandes potencias, Estados Unidos y Rusia, que, metafísicamente consideradas, son lo mismo: el imperio raso de la técnica que aplana y uniformiza todo lo humano.

Cabe notar que el "nacionalsocialismo privado" pretendido por Heidegger se relacionaba con sólo uno de los dos componentes del movimiento y la ideología nazis, movimiento que fue siempre una mezcla incongruente de tradicionalismo e innovación, de ruralismo bucólico e hipermodernismo, de retórica volkish, rescate de las "valores autóctonos", y tecnificación avanzada para la guerra más demoledora.

12 HEIDEGGER, Martin, Introducción a la metafísica [Einführung in die Metaphysik], Editorial: Nova, Buenos Aires, 1980

13 HEIDEGGER, Martin, "El Rectorado", en, Escritos sobre la Universidad alemana, Madrid: Tecnos, 1989, p. 32 
Heidegger tenía, más allá de esta incongruencia, una visión mítica de la comunidad de origen germánico definida en términos lingüísticos y geopolíticos, dentro de un clima cultural cuasi-rural y pastoril que vinculaba al Volk alemán con un pasado idílico cercano a los griegos, y con un futuro mesiánico ligado a la "salvación de Occidente". El pueblo alemán, "pueblo metafísico"14, es percibido por Heidegger como el portador de una misión histórica singular, y así como en 1929-30 el filósofo esperaba el arribo de una parousía que todavía se hallaba en el futuro, a partir de 1933 y por un tiempo $-y$ a pesar de sus fracasos políticos personales- consideró que el momento crucial de hecho había llegado.

Es así como Heidegger insinúa su entusiasmo revolucionario de los años veinte, aduciendo que las decisiones obedecen a los temples de ánimo. "En el año 1933 el temple de ánimo de Heidegger era el de una rehabilitación nacional de Alemania y un nuevo comienzo, tal como puede mostrarse con bastante precisión en base a los documentos recientemente publicados. La conquista del poder por parte del NSPAD en enero de 1933 conmovió a Heidegger, que se veía a las puertas de un cambio de época tan profundo y transformador como el del Renacimiento o el de la Reforma protestante. Lo mismo que en Napoleón veía Hegel cabalgar al espíritu del mundo, de igual manera Heidegger creía que con Hitler podía empezar una nueva época, nueva para Alemania y más allá de Alemania". ${ }^{15}$

Es así, únicamente dentro de este contexto global del oscurecimiento mundial que detecta Heidegger en su época, y que de distinta forma detectaron también mentes brillantes como las del filósofo e íntimo amigo de Heidegger, Karl Jaspers, como también Oswald Spengler, y otros por aquellos años, corresponde entender las palabras que cita Farías de la Conferencia en Bremen del año 45: "La fabricación de cadáveres en las cámaras de gas y la transformación de la agricultura en industria alimenticia son en esencia lo mismo"24. Ello sólo puede ser entendido en el contexto del pensamiento heideggeriano sobre la técnica, que acaba por suscitar que las cosas se muestren bajo su dominio nada más que como algo dispuesto, listo para ser utilizado, aprovechado y consumado.

14 HEIDEGGER, Martin, Introducción a la metafísica, [Einführung in die Metaphysik], Editorial: Nova, Buenos Aires, 1980, p. 43

15 SAFRANSKI, Rüdiger, "La política metafísica de Heidegger", En ABC Cultural, Madrid, 2003. 


\section{3.- Sloterdijk y Heidegger: Por una clarificación del claro (Lichtung).}

Situado pues en esta perspectiva crítica, Sloterdijk describe de manera paradójica su relación con Heidegger: 'con él'-contra él', 'íntimo y distante'. Sloterdijk piensa en la línea de Heidegger, aunque generalmente lo haga contra Heidegger. De este modo aunque Sloterdijk admite una deuda con Heidegger, en quien reconoce a alguien próximo que ha hecho un aporte decisivo al pensamiento moderno oponiéndose a la metafísica, al idealismo y al logicismo, él no deja nunca de ser un pensador originat, independiente y hasta inclasificable, un profundo conocedor de la tradición europea que a la vez honra y critica implacablemente.

Sloterdijk critica a Heidegger porque se detiene en la idea de verdad como revelación de lo escondido, sin explicar cómo llegó el hombre históricamente a tener esta capacidad de conocer la verdad que informa cabalmente la vida humana. La verdad en su sentido primordial es una posibilidad inseparable del hombre: ella le ocurre dinámicamente, sucede en el tiempo, es un ir y venir entre lo escondido y lo manifiesto. ${ }^{16}$ De la humanidad capaz de verdad se dirá, entonces, que es a la vez extática sin dejar de ser íntima. Esta doble condición de poder estar fuera de sí y adentro consigo es lo que hace posible que el hombre tenga mundo, una exclusividad que no comparte con nadie. De la humanidad capaz de verdad se dirá, entonces, que es a la vez extática sin dejar de ser íntima. Esta doble condición de poder estar fuera de sí y adentro consigo es lo que hace posible que el hombre tenga mundo, una exclusividad que no comparte con nadie. Ocuparse de la verdad es referirse "al lugar donde las cosas se vuelven manifiestas y también decibles o representables". ${ }^{17}$ La verdad nunca existe en estado puro o aislado sino que coexiste necesariamente con el error. Quien se ocupa de la verdad corre el riesgo de participar de los errores asociados a ella: aunque éstos sólo aparecen más tarde son siempre de temer. ${ }^{18}$ En este sentido, la posesión de una verdad que comprendemos y conserva su vigencia no es un refugio que proteja del error.

El claro es el lugar donde los plexos de significatividad que constituyen el mundo aparecen, se dan ontológicamente, pero, este mundo, parto del claro, no ha de responder a una actitud técnica, que es huida, olvido, renuncia, para Heidegger, sino, más bien, debe resguardar su principio, esto es, el de la diferencia ontológica. Prueba de estas inclinaciones ante la serenidad del mundo, llevado a cabo en las

\footnotetext{
16 SLOTERDIJK, Peter, Esferas III, Ed. Cit., p. 428.

17 Ibídem., p. 429.

18 VÁSQUEZ ROCCA, Adolfo, "Sloterdijk y Heidegger: las Repúblicas del saber, graneros y cultivos de la verdad; sobre la(s) historia(s) de la verdad o 'economía política de la verdad'", En ESPIRAL No 41 - 2012, Revista de Cultura y Pensamiento Contemporáneo, Tijuana, Universidad Autónoma de Baja California, México. http://www.revistaespiraltijuana.org/espiral_41/filosofia_adolfo.html
} 
últimas obras de Heidegger, es que, hasta el final de sus días, la interpretación que dio del ethos del Dasein, consiste en asegurar una permanencia en un lugar asignado al mundo, es decir, en desarrollar la teoría de lo que el mismo llamó el habitar. ${ }^{19}$

Sloterdijk interroga a Heidegger cómo llegó el hombre al claro (Lichtung) o como llegó el claro al hombre. Deberíamos saber cómo se produjo el relámpago, en cuya luz pudo iluminarse el mundo como mundo, aquello que Heidegger llamó el prodigio (Würde) de los prodigios, el ente develado, la verdad que se muestra. Y en el granero se acumula lo que se acredita como valioso ... "Al vertedero es arroja lo inútil e inauténtico. Verdadero es aquello que se guarda para volver a valerse de ello. La imagen del granero permite una asociación de las verdades, antes que puedan convertirse en objetos de colección y de cuidado, con una cosecha originaria que las junta para guardarlas". ${ }^{20}$ Como campo de cultivo de la verdad y lugar donde se acumulan los conocimientos, el aléthotopo es, pues, el sitio donde de veras se exhibe la apertura humana al mundo.

"Convertirse en mundo significa desvelarse de manera relevante para la yerdad. Lo que Heidegger llama el claro no designa sino esta relación fundamental. El término "claro" (Lichtung) es parte de la lógica y la poesía de lo monstruoso. Con él, la filosofía se cerciora de su posibilidad de ser actual y capaz de dialogar con los tiempos."21

Cuántos de quienes hoy en día están sumidos en la quiebra, en las bolsas de valores, por los imprevistos cambios en la economía mundial se preguntan por el Ser? "¿Quiénes se preguntan por el sentido último de la existencia y se asombran por el gran prodigio de que lo que es sea? $\dot{\imath}$ Acaso se interesan en reflexionar sobre el poderoso domino del mal y su rotunda presencia en todos los rincones de la tierra? Probablemente muchos, pero no quienes dirigen el destino de los demás:

"La mayoría de los hombres actuales que viven en las zonas más prósperas de la tierra se preocupa por cosas que tienen que ver con aspectos de una sociedad que se ha vuelto casi medieval, como el continuo crecimiento económico y la perpetuación de áctividades ciegas para sus consecuencias, por posesiones descuidadamente destructivas y derechos de explotación de la naturaleza". ${ }^{22}$

19 GARRIDO PERIÑÁN, Juan José, Ser y Lichtung: Heidegger ante el claro del ser. Desafíos fenomenológicos en torno al claro del ser, Editorial: Liber Factory (España) p. 59

20 SLOTERDIJK, Peter, Sin Salvación; Tras las huellas de Heidegger, Editorial Akal, 2011, Madrid, p. $100-101$

21 SLOTERDIJK, Peter, Sin Salvación; Tras las huellas de Heidegger, Editorial Akal, 2011, Madrid, p. 108

22 SLOTERDIJK, Peter, Sin salvación; Tras las huellas de Heidegger, Editorial, Akal, Madrid, 2011, Cap. I "Caída y vuelta (Discurso sobre el pensamiento de Heidegger en el movimiento)", p. 53 
Parece una tontería que ante los gravísimos problemas de la economía mundial alguien perciba la presencia de lo inquietante como la verdad fundamental del hombre contemporáneo. En estos tiempos no estamos para filosofar sino para actuar. En todo caso, hay algo en lo que tanto los hombres de acción como los filósofos están de acuerdo: "La Edad Moderna es la era de lo monstruoso hecho por el hombre". ${ }^{23}$

En el origen de toda filosofía está el asombro y "Heidegger modernizó el asombro convirtiéndolo en espanto". Es esa condición de lo "monstruoso", ese espanto el que debe tenerse presente para enfrentar el impulso aniquilador de la deriva actual, pues se está en el corazón del peligro -en referencia metafórica a la crisis mundial-. El balance es catastrófico y, sin embargo, hay que encontrar los caminos (claros) que reorienten hacia la verdad y retrasen la autoaniquilación. Heidegger opina melancólicamente que "la filosofía no podrá operar ningún cambio inmediato en el actual estado de cosas del mundo. Solo un dios puede aún salvarnos. La única posibilidad de salvación la veo en que preparemos, con el pensamiento y la poesía, una disposición para la aparición del dios o para su ausencia en el ocaso". ${ }^{24}$

La verdad acontece históricamente, de allí que aparezca siempre vinculada a un sitio habitado por hombres ( $y$ de una manera particular o característica para el grupo que vive en él). Su manifestación estará ligada al 'lugar'. En cuanto localización 'en la que ocurre', donde 'surge', donde ella 'se prueba', donde 'alguien la enuncia', donde lo dicho, conocido y revelado es conservado y difundido, pese a lo cual habrá una parte que queda latente y sin enunciar, el lugar de la verdad acoge a sus habitantes en un singular claroscuro. 25

Sloterdijk describe el proceso durante el cual segmentos de aquello que estuvo sustraído al conocimiento van pasando a formar parte de éste y lo liga tanto al tiempo como al espacio habitado por un grupo cultural. Por ejemplo, los pueblos que inventaron la investigación científica de la naturaleza en la modernidad pueden distinguir entre los fenómenos que aparecen desde sí y aquellos que han sido obligados a manifestarse mediante operaciones técnicas de búsqueda de lo escondido o desconocido. Un caso de mostración forzada resulta de las prácticas de la cirugía, que, aparte de sus funciones curativas, exhiben la interioridad de los cuerpos, que no había sido observada antes de tales intervenciones. En general sabemos que las técnicas modernas de

23 SLOTERDIJK, Peter, Sin salvación; Tras las huellas de Heidegger, Cap. VII "La época (criminal) de lo monstruoso", 2011 , p. 241

24 Alfredo Rocha de la Torre, Martin Heidegger: la experiencia del camino, Editorial Universidad del Norte, Barranquilla, 2009, p. 229.

25 VÁSQUEZ ROCCA, Adolfo, "El claroscuro de la verdad: Sloterdijk y Heidegger; observaciones aporéticas en torno a los conceptos de mundo, técnica y verdad", En REFLEXIONES MARGINALES, Revista de la Facultad de Filosofía y Letras, UNAM, Universidad Nacional Autónoma de México, Año 6. No 34 - 2016. http://reflexionesmarginales.com/3.0/el-claroscuro-de-la-verdad/ 
investigación no esperan pasivamente la manifestación de las cosas y las condiciones que le interesan, sino que las apremian a mostrarse mediante agresivas interrogaciones y experimentos. ${ }^{26}$

Ahora bien, Heidegger y Sloterdijk se entienden en el hecho de considerar a la técnica como un modo de abrir mundo: según la mirada que volquemos sobre lo existente, el espacio se abre ante nosotros de un determinado modo o de otro. Y de ese modo en que lo abrimos, lo habitamos. En la línea de Heidegger, podemos decir que no es lo mismo contemplar un bosque y ver en los troncos la morada de los espíritus de los árboles que mirarlo pensando en las toneladas de madera que obtendríamos de su tala. No es un bosque considerado de dos modos distintos: son dos bosques diferentes. La mirada técnica, entonces, construye el espacio y sugiere modos de habitarlo.

\section{4.- La Técnica como desocultamiento: sistemas de inmunidad e historia de lo monstruoso.}

Para Heidegger "la técnica es un modo de desocultamiento". Los modos del "dar-lugar-a" se dan dentro del producir donde el "dar-lugara" atañe a la presencia de lo que aparece en el producir. Éste acontece cuando llega lo velado a lo desvelado, es decir, se mueve y reposa en el desocultar. El desocultar es lo que nosotros llamamos verdad y el análisis revela que el "desocultarse se funda en el producir". 27 Lo que es la técnica moderna es un modo del desocultar pero que no se mueve en un producir sino en un "provocar" que fuerce a la naturaleza a liberar energías para que puedan ser explotadas y acumuladas. Este "provocar" se puede entender como un "poner" a la naturaleza, es decir, un exigir en sentido inicial de abrir y exponer pero ambas están superpuestas al otro sentido del exigir: lograr la mayor utilización con el mínimo de esfuerzo. La naturaleza con este provocar se encuentra supeditada a la esencia de la técnica moderna (ejemplo característico es el río Rhin en el que no se ha construido una central hidroeléctrica sino al revés, el río se ha construido-obstruido en la central: la naturaleza es desde la esencia de la central hidroeléctrica). Nos dice el autor que la esencia de la técnica es un desocultar que asume el carácfer de un poner en el sentido de un "provocar". ${ }^{28}$ Ésta descubre las energías ocultas de la naturaleza que son a su vez transformados, acumulados, repartidos y cambiados. Todo esto son modos del desocultar propios de la técnica moderna así como su desocultar propio al mostrar los medios a través de los cuales ella dirige.

26 Peter Sloterdijk, Esferas III, ed. Cit. Peter Sloterdijk, Sphären, 1998-2004, III, pp. 8081 n; cf. Sloterdijk, P. y Peter Weibel: Der ästhetische Imperativ: Schriften zur Kunst, 2007, pp. 396-397.

27 HEIDEGGER, Martin, "La pregunta por la técnica". En: Filosofía, ciencia y técnica. Op. cit., p. 113-148.

$28 \quad$ Ibídem 
Este augurio que insiste persistentemente en que la técnica es esencialmente desocultamiento o explicitación -más claro: un modo de violencia quebradora de latencia- se desaconseja seguir contando la explotación a gran escala del descubrir, inventar y publicar como la historia festiva del progreso humano del conocimiento. ${ }^{29}$ "La investigación, como trabajo sistemático de despliegue de lo no descubierto, ha de llevar, según Heidegger, a una malcomprensión cada vez más profunda del ocultamiento".30

Es así como el acontecimiento fundamental-aunque secreto- del siglo XX es la catástrofe de la latencia. Sus resultados más llamativos son la potencia nuclear instrumentalizada, los sistemas de inmunidad puestos de manifiesto, el genoma descifrado y el cerebro al descubierto.

No es casual que en las interpretaciones más recientes del fenómeno inmunidad se manifieste una tendencia a conceder a la presencia de lo extraño dentro de lo propio un papel mucho más importante de lo que estaba previsto en las concepciones identitarias tradicionales de un sí mismo organísmico monolíticamente cerrado: casi se podría hablar de un giro postestructuralista en la biología. ${ }^{31}$

Dentro del contexto global del oscurecimiento mundial que "detecta" Heidegger en su época, y que de distinta forma detectaron también mentes brillantes como las del filósofo e íntimo amigo de Heidegger, Karl Jaspers, como también Oswald Spengler, y otros por aquellos años, corresponde entender las palabras que cita Victor Farías de la Conferencia en Bremen del año 1945: "La fabricación de cadáveres en las cámaras de gas y la transformación de la agricultura en industria alimenticia son en esencia lo mismo".32 Ello sólo puede ser entendido en el contexto del pensamiento heideggeriano sobre la técnica, que acaba por suscitar que las cosas se muestren bajo su dominio nada más que como algo dispuesto, listo para ser utilizado, aprovechado y consumado.

La filosofía de Sloterdijk -una mixtura entre antropología, ontología, estética y politología- intenta dar cuenta del hombre como fracaso biológico a través del relato evolutivo del hombre como deriva biotécnica y biotecnológica. A partir de este gran relato-las tres figuras del animal político- se puede extraer, a grandes rasgos, el devenir histórico de las organizaciones políticas y sus particulares productos humanos. El planteamiento de Sloterdijk presenta la historia natural de la especie y la historia social de la domesticación humana, alineadas en un mismo relato coherente. Esto hace pensar que, para Sloterdijk, el

29 SLOTERDIJK, Peter, Esferas III, Ed., cit., pp. 176-177

$30 \quad$ Ibídem, p. 177

31 HARAWAY, Donna J. "The Biopolitics of Posmodern Bodies: Determinations of Self in Inmmune System Discourse", en: Differences, 1, 1, 1989.

32 HEIDEGGER, Martin, en: W. Schirmacher, Technik und Gelassenheit, Friburgo, 1985, p. 25. Citado por Víctor Farías, Heidegger et le nazisme, Verdier, París, 1987. 
último de los dualismos, la distinción entre naturaleza y cultura ha de ser eliminado. El hombre como "animalitas fracasada" 33 es, fundamentalmente, lo indeterminado que transforma el medio en su mundo, y desde el cual adquiere una determinación relativa. En este sentido, lo que hay de natural en el hombre no pasa de ser una inadaptación y una vulnerabilidad, pero que paradojalmente si se quiere, le proporciona un momento de primigenia apertura por la que se desencadena la revolución antropogénica, esto es, su devenir un producto técnico, una unidad de naturaleza y cultura indistinta; unidad en la que se hace patente el predominio del factor histórico-cultural. El individuo -ilusión del occidente contractual burgués- lleva en sí las marcas del trato con lo humano, de la genialidad y creatividad de lo humano, también del fuego, dolor y desesperanza de lo humano. Es él, en todo punto, una borrosidad incapaz de autoconocimiento si no se miente a sí mismo, si no aplica sobre sí toda la fuerza coactiva de una mirada reduccionista. Según Sloterdijk ya en la remota vida de las hordas comienza para los hombres "una historia natural de lo que ho es natural". ${ }^{34}$ La horda puede ser entendida como "la revolucionaria incubación de la antinaturalidad dentro de la propia naturaleza". 35 Según esto, la política de las primitivas hordas consiste en constituirse en "incubadoras de cría donde se prueba suerte con los más sorprendentes experimentos biológicos sobre la forma humana". 36

En el decir de Sloterdijk los seres humanos intuyen que no todo está iluminado. Sólo la parte más pequeña de todo lo que existe es accesible al saber actual y la percepción. La verdad acontece en la frontera entre estos dos reinos del ser: "el clarificado y el oscurecido". 37 El mundo como espacio iluminado se ofrece a los que han encontrado en él un lugar habitable para revelarles ciertas verdades, algunas tocantes al sentido de lo humano, o-simplemente- al (sin) sentido. "La revelación nunca es completa y es en principio imposible apaciguar la sospecha hacia lo que está encubierto y no se muestra. El mundo se perfila como un compuesto de evidencia y encubrimiento. Nunca es la sola suma de todos los cuerpos o los estados de cosas".38

33 VÁSQUEZ ROCCA, Adolfo, "Nietzsche y Sloterdijk; depauperación del nihilismo, posthumanismo y complejidad extrahumana", En NÓMADAS, Revista Crítica de Ciencias Sociales y Jurídicas - Universidad Complutense de Madrid, NÓMADAS. 25 | Enero-Junio.2010

http://pendientedemigracion.ucm.es/info/nomadas/25/avrocca.pdf

34 SLOTERDIJK, Peter, (1994) En el mismo barco; ensayo sobre la hiperpolítica, Sirvela, Madrid, 2008, p. 28

$35 \quad$ Ibídem., p.27 - 29

36 Ibídem., P. 28.

37 SLOTERDIJK, Peter, Esferas III, ed., cit. pp. 427-428.

38 SLOTERDIJK, Peter, Sin salvación; Tras las huellas de Heidegger, Editorial, Akal, Madrid, 2011, p. 93 y siguientes. 
El mundo es un espacio -en principio- aclarado, aunque cabe precaver -como lo hace Sloterdijk- que la constitución más propia de la realidad es la de la distribución originaria de lo oculto y de lo manifiesto, es decir "no todo está aclarado".

La esfera clara a la que hemos salido es una mancha de luz en medio del círculo de lo desconocido, no-manifiesto, no-dicho, no-pensado. Y en este círculo de lo sustraído se oculta, según la convicción de los antiguos, lo ontológicamente esencial, a cuya exploración habrán de dedicarse los sabios, esos inquietantes vecinos de nuestra esfera. La sensibilidad por la verdad de los seres humanos se desarrolla a partir de la intuición de que entre el ámbito aclarado y el oscurecido del ser tiene lugar un tráfico fronterizo no fácil de comprender.

Heidegger impresiona a Sloterdijk por su incomprensión del mundo moderno, incomprensión, piensa, ligada estrechamente a su rechazo de la racionalidad técnica, su conservadurismo político ${ }^{39}$ y su apego a la tierra. De allí que el claro-die Lichtung- de Heidegger sea una metáfora forestal, propia del imaginario filoagrario40 que no evoca el ámbito de las discusiones ciudadanas, entre las que cabe considerar, por ejemplo, el mercado. Por ello Heidegger no avanzó hasta la ciudad y su centro, hasta la plaza, el ágora o el foro, resultándole aún más ajeno aquello a que se llega trascendiendo la ciudad: el espacio político del Estado, las relaciones internacionales, el cosmopolitismo moderno. Heidegger como el último cerebro de la era agraria reaccionó contra la modernidad industrializada. Nunca entendió ni supo apreciar la navegación ultramarina, ${ }^{41}$ ni el capital, ni los medios de comunicación, en suma, el surgimiento del nuevo sistema del mundo, que es precisamente el tema que hoy ocupan a Sloterdijk. Así, en la perspectiva de Sloterdijk el rechazo heideggeriano de la antropología no sólo separa a la filosofía de fuentes de información indispensables, sino que, peor aún, es una actitud que excluye la posibilidad de que el pensamiento pueda nutrirse del rico saber empírico acumulado en las ciencias especiales.

El crecimiento del conocimiento y de la técnica no puede seguir siendo interpretado -señala Sloterdijk- como pretendía Heidegger, quien continuaba entendiéndolo, después de dos siglos y medio de metafísica

39 Carla Cordua, Sloterdijk y Heidegger; La recepción filosófica, Santiago, Ediciones Universidad Diego Portales, 2008, p. 28.

40 VÁSQUEZ ROCCA, Adolfo "Sloterdijk y Heidegger; Metáfora de la navegación, hiperpolítica y crítica del imaginario filoagrario" pp. 99 - 112 , En Peter Sloterdijk; Esferas, helada cósmica y políticas de climatización, Colección Novatores, № 28, Editorial de la Institución Alfons el Magnànim (IAM), Valencia, España, 2008.http://www.observacionesfilosoficas.net/sloterdijkyheidegger.htm

41 SLOTERDIJK, Peter, En el mundo interior del capital, para una teoría filosófica de la globalización, Sirvela, Madrid, 2007. pp. 60 - 77 (Cap. I.- Parte Sobre el surgimiento del sistema del mundo. 7.- Mundo de agua; Sobre el cambio del elemento rector en la Edad Moderna.) 
y técnica europeas, como los envíos del destino a la errancia de los hombres. La errancia (die Irre), la inevitable mixtura de la verdad con el error y el ocultamiento, propia de la condición de la existencia humana, es la forma dinámica con la que la existencia inauténtica se desplaza sin fin. La errancia es entendida como el extravío de la humanidad durante la época moderna, que, olvidando el ser, confía su existencia y su mundo a la técnica. Sloterdijk le reconoce a Heidegger que "para [él] era evidente que la errancia era duradera y grande". ${ }^{42}$

Para Sloterdijk, la labor-humana de mayor relevancia, y no sólo por su factura técnica, se forjó en el período más antiguo y nebuloso de la especie, específicamente, en la milenaria vida de las hordas, momento en el que se hace posible por primera vez la generación de hombres por parte de hombres, a saber, la antropogénesis. A este gesto grupal y psicosocial de la horda, Sloterdijk lo califica como paleopolítica, esto es, "el milagro de la repetición del hombre por el hombre". La antropogénesis sería, entonces, el legado más antiguo de toda tradición humana, y quizás también la función primordial a la que estuvo, alguna vez, ordenado el legado completo de la técnica. Esto permite, a la vez, develar el significado más profundo de lo monstruoso. Más allá del riesgo cotidiano de una catástrofe nuclear y de las fuerzas que la ciencia y la técnica modernas han liberado, lo monstruoso es una condición ontológica que consiste principalmente en el hecho de que el ser humano se concibe a sí mismo como gestor de sí. El progreso inquietante de la ciencia y la tecnología conduce a la constatación de la capacidad creadora de mundos de un ser que no tiene, en sí mismo, nada de divino. De la trascendencia a la inmanencia, el hombre se ha convertido en el resultado (no del todo previsible) de las lógicas y los dispositivos racionales engendrados en el corazón de la ciencia. Los desarrollos del conocimiento científico-técnico superan, con mucho, la capacidad racional del ser humano de prever sus efectos. He aquílo monstruoso. La posmodernidad (momento histórico en el que se sacan las consecuencias de la muerte de Dios) es aquella época en que lo monstruoso deviene cotidiano: afrontar directamente cuando afrontemos los escenarios posibles de futuro para nuestra especie.

Si el humanismo ha fracasado en su empresa; si lo que tenemos frente a nosotros cuando mentamos la palabra hombre es un proceso anónimo biocultural que se expone biológica e históricamente, entonces no hay algo que debamos abandonar con mayor premura que la idea de una esencia humana que se repite en todos y cada uno de los representantes de la especie. El concepto que Sloterdijk esgrime para plantear su oposición a la noción clásica de hombre se encierra en el concepto de hombre operable.

42 SLOTERDIJK, Peter, Sin salvación; Tras las huellas de Heidegger, Editorial, Akal, Madrid, 2011 , p. 140 
Sloterdijk se dedicará principalmente a caracterizar el lugar donde la verdad sucede y la manera cómo existe allí esa parte de sus habitantes que la conoce. En dirección contraria, refiere como algunas de las cosas sabidas caen en el olvido o se incorporan a lo implícito, a aquello que la vida del grupo da por descontado, pierde de vista y desconsidera como si no existiera. De este proceso, que tiene dos direcciones que atraviesan la frontera divisoria entre lo explícito y lo implícito, se sigue que la verdad no es la existencia determinada de cierto estado de cosas que pueda considerarse como estable y permanente; ni tampoco una propiedad definida de las proposiciones. Más bien es un ir y venir, ${ }^{43}$ el nexo entre una iluminación actual y un hundimiento en la noche atemática. En la medida en que lo presente, al parecer siempre igual, acapara toda la atención, perdemos de vista el carácter dinámico y situado del suceder de la verdad.

Como señala Sloterdijk:

Son fundamentalmente dos observaciones las que informan sobre la esencia de la verdad: en un momento dado, de lo desconocido envolvente salen novedades a lo sabido y dicho: al contrario, mucho de lo que se ha conocido retorna al olvido, a la léthe, a la implicación. En consecuencia, la verdad no es ni un contingente seguro de hechos ni una mera propiedad de las proposiciones, sino un ir y venir, un centelleo temático actual y un hundimiento en la noche atemática. Mientras el medio entre ambos, lo aparentemente igual-eterno y presente, reclame toda la atención, no queda libre mirada alguna para el aspecto dinámico del acontecimiento de la verdad. El necesario giro de la mirada a la temporización de la verdad lo han llevado a cabo pensadores como Hegel y, más aún, Heidegger". 44

El tráfico entre lo público-claro y lo oculto-oscuro troquelan acontecimientos, que "sobrevienen", pasan e inquietan al pensar. La diferencia entre proposiciones verdaderas y falsas se funda, por el contrario, en acciones que acaban con éxito (acertadas, apropiadas, concluyentes). Así, el mundo manifiesto viene dado desde el comienzo de dos maneras diversas: una, como nexo de acciones que realizamos, y otra, como conexión de acontecimientos que nos afectan. El doble sentido de verdad, como devenir-patente en el acontecimiento o en el resultado (en el está-bien del intento logrado) y como ser-enunciado en la frase apofántica, es tan viejo como la isla humana misma. ${ }^{45}$

Ahora bien, la verdad es la verdad del hombre, para Sloterdijk la indagación epistemológica nunca se trata de 'el ser en cuanto tal' sino de lo que hay allí para el hombre a propósito de su apertura al mundo; de allí que 'la verdad' se de o se produzca sólo a partir de la

43 SLOTERDIJK, Peter, Esferas III, ed. Cit., p. 327

44 Ídem.

45 SLOTERDIJK, Peter, Esferas III, Ed. Cit., p. 328 
ontogénesis de los espacios humanos, de la localización y espacialidad de los mismos, los que Sloterdijk describirá mediante "la metafórica" de las esferas o -si se quiere- de la ego-esfera, imaginario que remite mediante sus resonancias a las diversas formas del cuidado de sí. Cuidado y manifestación que tiene lugar a través de otros tantos fenómenos antropológicos fundamentales, sobre esto se volverá luego.

Ahora bien, este planteamiento y desarrollo de Sloterdijk se haya en la línea de Heidegger. Tal como señala Gianni Vattimo:

El ser del hombre consiste en estar referido a posibilidades; pero concretamente este referirse se efectúa no en un coloquio abstracto consigo mismo, sino como existir concretamente en un mundo de cosas y de otras personas. El modo de ser medio y cotidiano del hombre, del cual decidimos partir, se presenta ante todo como ser en el mundo". 46

\section{5.- La constitución existencial del Dasein; notas del traduttore.47}

El término alemán para designar 'existencia' es Dasein, -en su uso tradicional- que sigue la traducción de Gaos, es 'ser o estar aquí o ahí'. En la traducción de Jorge Eduardo Rivera, 48 en cambio (cabe precisar) el uso que Heidegger da a la palabra alemana "Dasein", en un sentido lato, coloquial, puede significar "existencia", sin embargo Heidegger la reserva para "el ente que desempeña el papel principal dentro de la pregunta por el ser"; o sea, el hombre. Se trata pues de una ontología centrada en el ser al que "le va" su propio ser, o el Dasein; y que puede ser una versión refinada, fenomenológicamente depurada, de lo que en otras tradiciones llamaríamos "sujeto", o lisa y llanamente "el ser que somos"; sólo que en sus reclamos de ser, de existir y de orientarse hacia los misterios ontológicos y metafísicos.

Pues bien, el traductor chileno no solo cuestiona que Gaos traduzca Dasein como "ser-ahí", además toma la decisión de dejarla en alemán ${ }^{49}$ en su texto: "En buen castellano habría que decir 'estar-ahí'; pero estarahí' significa existencia, en el sentido tradicional; es decir, algo enteramente diferente de lo que quiere decir Heidegger con la palabra Dasein", explica en su prólogo.

46 VATtIMO, Gianni, Introducción a Heidegger, Editorial Gedisa, Barcelona, 1998, p. 27

$47 \quad$ La mayoría de los traductores conocen la expresión "traduttore, traditore" que significa "traductor: traidor" y tienen sus propias experiencias personales con las dificultades de la traducción. En italiano suena mejor que en ningún idioma: traduttore, traditore.

48 HEIDEGGER, Martin, Ser y Tiempo, Traducción de Jorge Eduardo Rivera. Trotta. Madrid, 2003. Publicada originalmente por la Editorial Universitaria de Santiago de Chile en 1997.

49 Se trata de una solución puesta en práctica por muchos traductores de Heidegger desde hace más de dos décadas. Lo hallamos, por ejemplo, en la versión francesa de 'Ser y tiempo', debida a François Vezin. 
Ahora, más que una solución esto puede ser es renuncia. Rivera pudo aprovechar nuestro idioma: "En atención a recuperar la fecundidad filosófica de nuestro singular y exclusivo término castellano 'estar' y en vistas de que Rivera ya había cometido la osadía de traducir 'ser-en-elmundo' (In-der-Welt-sein) como 'estar-en-el-mundo', podría tal vez perfectamente haber traducido Dasein como 'estar-ahí'.

Está claro que, al dejar una palabra del idioma original, se atrae la atención sobre algo que en el idioma original no pretendía ser destacado. Dasein en alemán no es un 'concepto' inventado por Heidegger. Es la palabra de uso corriente para decir 'existencia'". Sin embargo usar Dasein tiene la ventaja de no perder la "proliferación semántica y filosófica que esta palabra permite en alemán", pues, explica, "Heidegger insiste mucho en 'Ser y tiempo' sobre la composición de esta palabra: el Da (el 'ahí' como locución locativa), y el Sein (que indica el ser pero también el estar)". Mientras la versión de Gaos acaba siendo una traducción con cierto carácter artificial, la de Rivera es más bien hermenéutica, incluso hay cierta "belleza literaria" y "estilo" en ella. $\underline{50}$

Como contraparte de esa ganancia, hay un cierto "desmedro filosófico", ya que cuando ciertas palabras importantes se traducen de distinta manera a largo del texto. Ocurre, por ejemplo, cuando Heidegger dice que la conciencia tiene el carácter de una "llamada" al ser humano que puede ser una "interpelación" para "intimarlo". Pues bien, las respectivas palabras en alemán son: Ruf , Anruf y Aufruf. Estas posibilidades de la llamada de la conciencia, con sus respectivas distinciones, significativamente se pasan por alto.

Pero qué señala el propio Rivera sobre su traducción, en 2005 publica:

Quisiera explicar la no traducción de la palabra "Dasein". En esto he obrado de acuerdo con el propio Heidegger. Es verdad que se trata de un recurso extremo, del que solo se ha de echar mano cuando es absolutamente necesario. La traducción de "Dasein" por "ser ahí" es definitivamente mala. Primero, porque en castellano no se dice "ser ahi" sino "estar ahi". 51

50 Juan Rodríguez M., "Esplendor y límite de la traducción chilena de "Ser y tiempo", de Martin Heidegger: Un libro clave del siglo XX", Artes y Letras, El Mercurio, domingo, 14 de junio de 2015, Quinta edición

51 Y frente a la objeción de que "estar" parece indicar algo pasaje- ro, debo decir categóricamente que eso es una mera apariencia: los muertos "están" bien muertos, y el pasado "está" definitivamente pasado. Lo que ocurre es que el carácter de actualidad (y también de "actualidad", como diría Zubiri) es frecuentemente pasajero, y ese carácter es precisamente lo dicho por el verbo "estar": "estoy cansado" significa: "estoy ahora, efectivamente, cansado"; el cansancio, que era una posibilidad se ha hecho actual en mí. Ninguna palabra puede expresar mejor la condición de ser del Dasein que nuestro castellano "estar". Tanto es así que se ha 
Ahora bien, "estar ahí" es lo mismo que "existir", en el sentido tradicional de esta palabra, que es lo que Heidegger llama "Vorhandensein" o "Vorhandenheit", o sea, un modo de ser que jamás corresponde al Dasein. Podría quizás traducirse "Dasein" por "estar en el ahí", que sería una traducción correcta, pero excesiva-mente larga para una palabra que se repite tan frecuentemente en Ser y tiempo (2.159 veces, fuera de sus variantes). También se ha pro-puesto (Julián Marías) la palabra "existir", entendiendo esta palabra en su sentido existencial y no en el sentido que tiene tradicionalmente. Pero esto, fuera de que complica un poco las cosas, tendría el inconveniente de que Heidegger dice que "Ia esencia del Dasein es la Existenz", que habría que traducir por: "la esencia del existir es la existencia" que, además de ser una frase sumamente equívoca, "puede parecer un poco zonza".52

Al retornar del breve excurso filológico-hermenéutico, cabe apuntar que la noción del Dasein es usada por Heidegger para indicar el ámbito en que se produce la apertura del hombre hacia el Ser. Inicialmente el término había sido identificado con la existencia del hombre, pero el propio Heidegger, en su "Carta sobre el Humanismo" de 1947 rechaza esta interpretación. De forma más precisa, podemos decir que Dasein alude al hombre como único ente que vive fuera de sí, abierto constantemente al Ser y a sufrir una revelación de Él.

Existencia, Dasein, ser en el mundo, son pues sinónimos. Los tres conceptos indican el hecho de que el hombre está "situado" de manera dinámica, es decir, en el modo del poder ser o también, como dirá Heidegger poco después, en la forma del "proyecto".

El hombre está en el mundo siempre como ente referido a sus posibilidades propias, es decir, como alguien que proyecta; y encuentra las cosas, en primer lugar, incluyéndolas en un proyecto, es decir, asumiéndolas, en un sentido amplio, como instrumentos. Instrumento en este sentido es también la luna, que al iluminar un paisaje nos sume en un estado de ánimo melancólico; y en general también la contemplación "desinteresada" de la naturaleza coloca siempre a ésta en un contexto de referencias, por ejemplo, de recuerdos, de sentimientos o por lo menos de analogías con el hombre y sus obras.

La disponibilidad revela el hecho de que el proyecto que constituye el Dasein es siempre un "proyecto arrojado" ("Ianzado") y esto pone de manifiesto la finitud del Dasein. En efecto, en la disposicionalidad nos encontramos siendo sin poder dar, radicalmente, razón de ello. El Dasein

propuesto traducir "Dasein" por "estar". El inconveniente de esta traducción es que requeriría explicaciones, y una traducción que requiere explicaciones es una mala traducción. Una cosa es explicar el texto de Heidegger después de haberlo leído, y otra muy diferente, no poder leerlo sin explicaciones.

52 Jorge Eduardo Rivera, "Sobre mi traducción de 'Ser y tiempo'"- Onomázein, Revista de lingüística, filología y traducción de la Pontificia Universidad Católica de Chile, 12 (2005/2): 157-167 
es finito por cuanto el proyecto sobre el mundo que constituye su ser no es un supuesto que él pueda "resolver" y cumplir, como quería Hegel. El mundo se nos aparece siempre, originariamente, a la luz de cierta disposición emotiva: alegría, miedo, desinterés, tedio. Todo los afectos singulares son posibles sólo como especificaciones del hecho de que el Dasein no puede estar en el mundo ly, por lo tanto, las cosas no pueden dársele) si no es a la luz de una disposicionalidad que, radicalmente, no depende de él.

Todo esto es de suma importancia porque nos lleva a cuestionar el concepto mismo de realidad como simple presencia. La filosofía y la mentalidad común piensan desde siglos que la realidad verdadera de las cosas es la que se aprehende "objetivamente" con una mirada desinteresada que es, por excelencia, la mirada de la ciencia y de sus mediciones matemáticas. Pero si, como se vio, el modo de presentarse originario de las cosas en nuestra experiencia no es aparecer como "objetos" independientes de nosotros sino que se nos dan como instrumentos, queda abierto el camino para reconocer la objetividad misma de las cosas como un modo de determinarse particular de la instrumentalidad. ${ }^{53}$ La objetividad es algo a lo que se llega (y sobre esto está de acuerdo aun la metodología científica) en virtud de una operación específica en la cual se "hacen a un lado" los prejuicios, las preferencias, los intereses, para ver la cosa tal como es "en sí". Pero esta operación es sin embargo, inevitablemente, una operación del hombre, que éste lleva a cabo precisamente; con miras a ciertos objetivos precisos: la conexión de las ciencias objetivas modernas con la técnica no necesita ser documentada. La simple presencia se revela así como un modo derivado de la utilizabilidad y de la instrumentalidad que es el verdadero modo de ser de las cosas.

Sobre la base de todo esto se puede entender fácilmente gran parte del desarrollo ulterior de la analítica existenciaria. Los pasos dados hasta aquí nos mostraron ya cómo la simple presencia no sólo es inadecuada para concebir el ser del hombre, sino que es un modo de ser sólo parcial y derivado también de las cosas diferentes del hombre (de los entes intramundanos, como dice Heidegger). La simple presencia es un modo en el cual las cosas se manifiestan en relación con una operación precisa del hombre; y, en general, las cosas no son "en sí", sino que ante todo están en relación con nosotros como instrumentos; su ser está radical y constitutivamente en relación con el ser proyectante del Dasein. Este es el primer paso para llevar a cabo una revisión general del concepto de ser.

53 VATTIMO, Gianni, Introducción a Heidegger, Editorial Gedisa, Barcelona, 1998, pp. $28-29$ 


\section{6.- La pregunta por la técnica y por el ser de lo útil.}

Para Heidegger el desocultar imperante de la técnica "pone a la naturaleza ante la exigencia de liberar energías, que en cuanto tales pueden ser explotadas o acumuladas".54 Heidegger designa Gestell a la forma en la cual el ser se des-oculta al hombre contemporáneo. El campo, el mar, los bosques, el hombre mismo son desencubiertos como entidades cuyo rasgo fundamental es la utilización (explotación) sin límites. El ente va quedando reducido a a fondo de "existencias" en el sentido de stock o depósito (Bestand), "reservas" para el desocultar provocante de la técnica moderna. La madera talada, en la lógica y cadena productiva de la celulosa que, a su vez, viene pro-vocada por la necesidad de papel, que se distribuye a los diarios y revistas ilustradas, soporte de la prensa, ya que predisponen a la opinión pública a que devore lo impreso, para que pueda llegar a establecerse una opinión dominante, que hay que establecer".55

En palabras del mismo Heidegger: "La naturaleza se convierte en una única y gigantesca 'estación de servicios' en fuente de energía para la técnica y la industria modernas".56 La naturaleza viene a ser así el principal almacén de existencias de energías. La naturaleza comparece ante el hombre como entidad prágmática. "El bosque es reserva de madera, el cerro cantera, el río energía hidraúlica, el viene es viento 'en las velas"'.

Heidegger señala que el Dasein se encuentra siempre ocupado en el complejo referencial de los útiles (Zeuge). "Estar en el mundo" significa "absorberse atemática y circunspectivamente en las remisiones constitutivas del estar-a-la-mano del todo de útiles"57, es decir, estar inmerso en el trato con los prágmata. De tal manera el modo inmediato del trato entre Dasein y ente intramundano no es el conocer puramente aprehensor, sino el ocuparse que manipula y utiliza, el cual tiene su "conocimiento". En el trato cotidiano con los útiles predomina entonces la Umsicht (circunspección), no homologable a la visión teorética de un sujeto que se «representa» objetos. En una extensa descripción analítica, Heidegger emprende su famoso 'análisis de los útiles', de lo que esta a la mano, "las cosas" -pragmatas-. El útil remite al que lo manipula, al que lo usa; es tal sólo porque alguien, al necesitarlo, lo emplea como utensilio (las cosas no tienen un caracter sustancial, sino relacional, se ordena hacia la función que le es propia). Los ùtiles no funcionan aislados sino en plexos utilitarios co campos pragmáticos. Como un

\footnotetext{
54 Martin Heidegger, "La pregunta por la técnica", en Ciencia y técnica, Ed. Universitaria, Santiago, 1984, pp. 81 ("Die Frage nach der Technik", p. 14)

55 Martin Heidegger, "La pregunta por la técnica", en Ciencia y técnica, Ed. Universitaria, Santiago, 1984, pp. 85 y s. ( "Die Frage nach der Technik", pp. 17 s.)

56 Martin Heidegger, "Serenidad"; en Revista Eco Tomo I, N. ${ }^{\circ}$ 4, Bogotá, 1960, p. 114 ; Trad. De Antonio de Zubiaurre (Gelassenheit, Neske Verlag, Pfullingen, 1959, p. 20)

57 Martin Heidegger, Ser y Tiempo, Trotta. Madrid, 2003, p. 103
} 
martillo está 'incorporado' en el uso mediante su remoción; cómo es apropiado, no como objeto, sino como elemento que es parte de los utensilios en un sistema de asignaciones o contexto. De ahí que la actividad de la praxis propiamente humana es "el tipo de relación que está más cerca de nosotros (...) no es una cognición perceptual vacía, sino más bien ese tipo de interés que manipula las cosas y las pone en uso; y esto posee su propio tipo de 'conocimiento"'. El martillo no es, así, en primer lugar un objeto-en-sí-mismo, sino que es un componente dentro de un contexto de uso (Zeugganzheit) que incluye un conjunto completo de herramientas, implementos, máquinas, materiales, energías; entidades materiales (los clavos, los zapatos a los que se les pondrán suelas, el taller, etc.). Esto implica que el uso de un útil está dirigido-y necesariamente refiere-a otro útil. En la experiencia ordinaria no hallamos items singulares o autosuficientes. Más bien, el útil se encuentra siempre inmerso en un complejo remisional. Es evidente que -en tal contexto-resulta imposible identificar cierto objeto en cuanto a su funcionalidad sin establecer su dependencia en relación con ciertos nexos de sentido, nexos que remiten tanto a un horizonte más amplio de objetos como a una estructura de acciones intencionales posibles.

\section{7.- Soportes antropotécnicos-egotécnicos. Vuelta sobre la Técnica y los cultivos de la verdad.}

Ahora bien, para Sloterdijk, la verdad es la verdad del hombre, la indagación epistemológica nunca se trata de "el ser en cuanto tal" sino de lo que hay allí para el hombre a propósito de su apertura al mundo; de allí que "la verdad" se de o se produzca sólo a partir de la ontogénesis de los espacios humanos, de la localización y espacialidad de los mismos, los que Sloterdijk describirá mediante "la metafórica" de las esferas o -si se quiere- de la ego-esfera, imaginario que remite mediante sus resonancias a las diversas formas del cuidado de sí. Cuidado y manifestación que tiene lugar a través de determinados fenómenos antropológicos.

Asimismo la ego-esfera nos proporciona las rutinas para el cuidado de sí, que fortalecen la individualidad. Pero más allá de las rutinas del día a día, encontramos cuatro fenómenos antropológicos que podemos ver explícitos y claros en el apartamento. Fenómenos para la formación y la conformación de la individualidad, gracias a los soportes antropotécnicos-egotécnicos. A saber: el quirotopo (las manos y el trabajo), el fonotopo (los medios sonoros y los silencios de lectura), el erototopo (el amor y el erotismo), el ergotopo (el ejercicio y el cuidado de sí) y, por último, el alethotopo (las luchas por el saber y el conocer), lo que Foucault -en un giro nietzscheano- llamará voluntad de saber. ${ }^{58}$

58 SLOTERDIJK, Peter, Esferas III, Ed., cit., pp. 290 y siguientes. 
Llamaremos entonces alethotopos al lugar en el que cosas se vuelven manifiestas, decibles o figurables, las repúblicas del saber y el acontecer de la verdad. Sin embargo la estancia en él encierra el riesgo de ser influido tanto por verdades que se muestran, se comprenden y siguen valiendo, como por errores, que sólo se manifiestan posteriormente como tales y cuya repetición es de temer. Desde el primer punto de vista, el alethotopo se parece a un almacén, desde el segundo, a un lugar de ejecución o a un vertedero de basuras. En el almacén se guarda lo que se acredita como verdadero: no en vano la palabra alemana para verdad [Wahrheit] tiene que ver con conceptos como asistir, tutelar, proteger, conservar, defender, cuidar. En el lugar de ejecución, o en el vertedero de basuras, por el contrario, se elimina lo que el grupo no puede ni quiere mantener dentro de él, en tanto que es malvado, defectuoso, inútil y nulo. Verdadero es lo que se conserva para su reutilización. La imagen del almacén permite la asociación siguiente: las verdades, antes de que puedan convertirse en objetos de colección y guarda, tienen que ser cosechadas en una recolecta originaria, muy en consonancia con la referencia de Heidegger al sentido, muy naturalizado en la agricultura, del verbo griego légein, cosechar, recolectar, recoger las uvas, coger flores, fruta, etc., cuya substantivación en lógos produce el concepto de razón y discurso en la antigua Europa. Desde ese punto de vista, el alethotopo, como campo de cultivo de la verdad y punto de recogida del conocimiento, es el auténtico escenario de la apertura humana al mundo. A partir de esto puede comprenderse también por qué los modernos medios de almacenaje sólo muestran ya una conexión marginal con las circunstancias humanas: porque en ellos, como en todos los archivos cognitivos, se hacen colecciones a-subjetivas: amontonamientos de información para nadie.

Se podría decir que desde la ilustración se han incrementado las manifestaciones y develaciones epistémicas, y por lo tanto, un incremento de verdades en ese espacio-almacén que llamamos 'alethotopo'. La ilustración científica y filosófica con su carácter inquisitivo y sus medios tecnológicos, no se conformó con meras contemplaciones pasivas, sino que se esforzó en ir -o arremeter- más allá de los límites de las representaciones comunes y forzó a la naturaleza a comparecer ante el feróz tribunal de la técnica, lo que produjo un exceso de respuestas y verdades. Esto podría parecer enriquecedor para nuestro almacén, sin embargo, donde se da una gran riqueza, se da también un gran despilfarro, derroche y excedente. ${ }^{59}$ Donde se descubren muchas verdades, también se corre

59 Como señala J. L. Pardo la relación existente entre riqueza y basura, y aunque lo explica hablando de la excesiva riqueza producida por el capitalismo, y por lo tanto la excesiva basura que produce este, bien podríamos usar su ecuación para la verdad, si es que tenemos que estar de acuerdo en que "la verdad tiene un lugar". Pardo nos dice que basura es aquello que no tiene lugar, aquello que tiene que ser 
el riesgo de caer en errores, develaciones inútiles e improductivas o -lo que es más temible: el desarrollo de tecnologías que por medios aleatorios dan lugar a armas biológicas, virus o fusiones atómicas que escribirán la historia de la devastación humana.

\section{6.- La época de la tecnociencia}

El pesimismo de Heidegger contrasta con el espectacular desarrollo de la ciencia y la técnica en el siglo XX. Es el siglo en que Einstein formula la teoría de la Relatividad General (1916), Fleming descubre la penicilina (1929) y Bohr y Heisenberg establecen los fundamentos de la mecánica cuántica. En 1924, Broglie sienta los principios de la mecánica ondulatoria al describir el comportamiento del electrón y, tres años después, en 1927 (la misma fecha en que se publica Ser y tiempo), Georges Lemaître elabora un modelo del universo que, de acuerdo con las teorías de Einstein, postula una expansión sin un centro de referencia, hipótesis confirmada más adelante por el astrónomo norteamericano Edwin Hubble, con sus observaciones sobre la distancia a Andrómeda y su composición estelar. En 1932, se descubre el neutrón y, algo más tarde, la radioactividad. En 1938, Strassman y Hahn logran la fisión nuclear.

Después de la Segunda Guerra Mundial, surgirán la cibernética, los transplantes de órganos, el rayo láser, el hallazgo del ARN y el ADN, el primer alunizaje y los microprocesadores. Nada de esto modifica la perspectiva de Heidegger, que responsabiliza a la ciencia de alejar al hombre de su cometido esencial: pensar el ser. El progreso tecnológico ha olvidado esa tarea, rebajando la naturaleza a pura objetualidad sometida al ser humano por una relación de dominio. Frente a la técnica moderna, "que exige a la naturaleza suministrar energía que como tal pueda ser extraída y almacenada", Heidegger evoca la techné griega cuyo producir no consiste en fabricar cosas, sino en un "llevar a la presencia" el ser del ente.

No hay en Heidegger una sola palabra sobre Auschwitz. Jean Améry, pensador austriaco y superviviente del famoso campo de exterminio, considera que el genocidio nazi pone de manifiesto la indigencia del pensamiento heideggeriano. La "palabrería vacía" de "ese desagradable mago del país de los alemanes" mostraba toda su miseria en el espacio acotado por las alambradas, pues "en ningún otro lugar del mundo la realidad poseía una fuerza tan imponente. Bastaba con ver la torreta de vigilancia y sentir el olor a grasa calcinada procedente

depositado o llevado a otro sitio, a un terreno baldío, a un no-lugar (como lo denomina Marc Auge), o a un lugar-basura, con la esperanza de que eso pueda progresar y desaparecer como lo que actualmente es, basura. Sin embargo, en un mundo donde ya no queda espacio para la basura, en un mundo lleno, ¿̇ónde trasladar aquello que no tiene lugar aquí? 
de los crematorios" para advertir que el Ser sobre el que gira la filosofía de Heidegger sólo era "un concepto abstracto y huero".

El silencio de Heidegger ante la mayor tragedia de la historia europea puede interpretarse como el efecto de un pensamiento despegado de lo inmediato, cuya finalidad -pensar el ser- se inscribe en un dominio atemporal.

\section{La técnica, según Heidegger, es un modo del develar el ser, es un modo} en el que lo real aparece, de-viene, pero es un modo del develar violento y que conmina a la tierra a mostrarse como útil, como manipulable, liberando energía para acumularla y utilizarla. La tecné es una modalidad de la poiesis, del producir. Lo radicalmente propio de la técnica es que implica el develamiento (aletheia) violentando, y en tanto modo del develar implica la iluminación y la ocultación simultánea. De allí que la técnica muestra a los entes, pero deja de lado al ser desde donde son entes; muestra a la vez que oculta algo de ellos. "La técnica moderna se da como modo del develar pero no en el sentido de la poiesis, como creación que pone en libertad el ser del ente, sino como provocación y violentamiento del ente".60

La técnica es "una manera de desocultar" -un producir y hacer presente el ente utilizando instrumentos de naturaleza lógica y material-, la pregunta por las producciones de las que ha resultado el hecho hombre adquiere un significado que no puede separarse de la pregunta por la "verdad" de este ente. [...] La condición humana es, pues, enteramente producto y resultado, pero producto de realizaciones que hasta ahora raras veces han sido adecuadamente descritas como tales, y resultado de procesos sobre cuyas condiciones y reglas se sabe demasiado poco.61

Heidegger propone al pensamiento una nueva tarea "ética", a saber el retorno a la tierra natal, a la proximidad al ser, que es al mismo tiempo olvido de sí, pérdida originaria de una verdad que se da retirándose. Por ello, este regreso al hogar debe entenderse a partir de la ausencia de tierra natal del hombre moderno, es decir, a partir del olvido del ser característico de Occidente e inducido por el ser mismo: "El desterramiento así pensado reside en el abandono del ser de lo ente. Es la señal del olvido del ser (...)".62 Se trata de reconducir a la tierra natal fuera de toda perspectiva nacionalista y nostálgica del origen étnico, del paraíso perdido. Esta tierra natal no es, en efecto, ni Alemania ni Occidente, sino la esencia del hombre, su proximidad esencial al ser tanto en su presencia cuanto en su disimulación: la ausencia de tierra

60 Ricardo Horneffer, "Heidegger, guardián del ser", En Martín Heidegger. Caminos, Ricardo Guerra Tejada y Adriana Yáñez, Coordinadores, Ed. Universidad Nacional Autónoma de México, 2009, p. 120.

61 SLOTERDIJK, Peter, Sin salvación, tras las huellas de Heidegger, Ed., cit., p. 100

62 HEIDEGGER, Martin, "Carta sobre el Humanismo", p. 278. 
natal forma parte del retorno a ella. Este retorno permitiría distanciarse del predominio de la técnica y de su modo característico de pensar para conducir a la proximidad al ser en el seno de su historia. La relación con el ser puede ser pensada, en consecuencia, en la perspectiva de una pertenencia común de los hombres a la historia del mundo, de su proximidad esencial a un origen que no siempre ha sido declinado en los términos del ser. Esta visión de la historia del mundo permitiría vincular Occidente y Oriente en un destino común, en una comunidad de origen que, en Occidente, Heva el nombre de "ser". La pregunta que surge es, entonces, ¿quién define este origen y la dirección de este

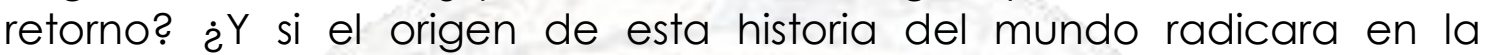
condición primera de extranjero, este extranjero sin tierra natal, la alteridad radical del Otro? Es así que Heidegger retirado de la vida académica, muere en su localidad natal el 26 de mayo de 1976, cumpliendo su propósito de permanecer en el origen, en esa "proveniencia" donde el pensador se sentía "en su propia morada".

Refirado de la vida académica, muere en su localidad natal el 26 de mayo de 1976, cumpliendo su propósito de permanecer en el origen, en esa "pro-veniencia" donde el pensador se siente "en su propia morada".

Reconociendo que la obra de Heidegger sostiene originalmente que lo patente o manifiesto procede de una autopublicación del ser en el claro o Lichtung, Sloterdijk somete esta idea de la verdad a una crítica muy atendible. Heidegger, el testigo de las dos guerras mundiales y de la creciente tecnificación del mundo en torno, debió haber llegado a comprender que esta noción de la verdad como descubrimiento donado por el ser, que había sido inspirada originalmente por el pensamiento griego temprano, era incompatible con las revelaciones acerca de la verdad ligadas a la investigación científica moderna y a sus complejas intervenciones técnicas con los procesos de la naturaleza. La ciencia moderna se caracteriza por forzar al curso de las cosas a mostrarse, interviniéndolo hasta lograr lo que busca. La revelación de su ser y su organización no procede de lo investigado, sino a partir de la interrogación a que se lo somete y de los motivos que la inspiran. Las cosas tratadas como objetos son doblegadas por la experimentación que es diseñada de antemano con el fin de provocar una manifestación.

Pensar al homo humanus significa dar cuenta del nivel en que rige la ecuación de ser humano y claro. Tal como sabemos ahora, el claro, empero, no puede pensarse pasando por alto su origen tecnogénico. El hombre no se encuentra en el claro con sus manos vacías, ni como un 
pastor alerta, inerme junto al rebaño, como sugieren las metáforas pastorales de Heidegger. 63

En palabras de Sloterdijk:

En el mundo de la técnica, lo que no es patente es llevado a manifestarse mediante una ruptura programada de la latencia; o es arrancado de un contexto en que no es perspicuo para conferirle, con ayuda del diseño y las técnicas de presentación, una presencia sensible artificial; o es conducido desde su condición no manipulable hasta colocarlo en una segunda disponibilidad. Et saber creado por la investigación y el descubrimiento es un saber iluminado por una lámpara de neón. En el lugar de la claridad propia del ser entra la claridad forzada de "lo dado" (das Gegebene); en vez de la percepción orgánica, lo operante es la observación organizada.64

El refinamiento cognitivo del hombre lo faculta desde los comienzos para enterarse de que, más allá del mero ámbito de la atención y del entorno, cabe esperar que el 'mundo' ofrezca más de lo que ha mostrado de sí. Gracias a esta experiencia es lícito llamar al hombre 'el animal formador de mundos', si con ello se quiere decir que recoge y sigue escribiendo el texto del mundo.

La posición crítica de Sloterdijk frente a la idea de verdad de Heidegger se centra en que la verdad entendida como develamiento presupone la existencia permanente de lo oculto, es decir, el ser es ligado permanentemente al descubrimiento de lo que antes estuvo sustraído al saber de los hombres. Si esto es así, cabe preguntarse -señala Sloterdijk¿Qué clase de ser (cuál es el estatuto ontológico o qué tipo de 'realidad es' aquella que) puede atribuirse a las cosas antes de que fueran descubiertas? Desde la perspectiva de Sloterdijk ya en la pregunta misma -supuesta o derivada de la concepción heideggeriana- conduce a dos errores característicos -y de alguna forma complementarios-, a saber las respuestas del idealismo y del realismo ingenuo. La primera dice que lo descubierto carecía de una manera de ser determinada antes de su descubrimiento. Aquello a lo que le falta un testigo pensante carece de ser. La segunda les atribuye a las cosas todavía no descubiertas un ser objetivo independiente de saber: las cosas poseen un ser anterior al momento en el que son encontradas y percibidas. La inteligencia no las afecta de modo alguno: lo que son en sí no varía con su descubrimiento contingente por el pensamiento.

Estas dos respuestas resultarán desorientadoras ya que tenderán a hacer pensar que la distancia entre lo patente y lo escondido puede ser desgastada por una voluntad decidida hasta hacerla desaparecer

63 SLOTERDIJK, Peter, "El hombre operable. Notas sobre el estado ético de la tecnología génica", Revista Laguna, 14; marzo 2003, p. 16

64 SLOTERDIJK, Peter, Esferas III, Ed., cit., p. 227 
mediante la continua reducción de lo escondido en favor de lo patente, o incrementando lo explícito a costa de lo implícito. Pero esta noción de un progreso indefinido de la verdad no es compatible con la convicción de Heidegger, quien se pronunció claramente sobre ello al decir que la técnica era un modo de patencia o develamiento del ser. Si la verdad es un suceder que se ha vuelto violento en la época moderna, ¿̇qué consecuencias se siguen de ello? El descubrimiento, la invención reveladora y la publicidad universal entran en el terreno de lo que se encuentra disponible para la voluntad de poder. Hasta aquí los hombres confiaban en su pertenencia al orden conjunto del ser en el que su propia existencia poseía un sentido garantizado, aunque no fuera siempre obvio cómo interpretarlo. Los filósofos se desempeñaron siempre como inmunólogos del ser, dándole una importancia inestimable a la verdad, cuyo conocimiento era la mejor garantía para la vida. El todo omniabarcante, perfecto, inmortal y benéfico de la metafísica tradicional amenaza con desaparecer en favor de una realidad neutra infinitamente variada en la que ninguna diferencia hace diferencia alguna. Sloterdijk considera que en circunstancias en que el mundo se ha convertido en el escenario en el que todos se devoran unos a otros (Schauplatz gegenseitiges Verzehrs), creer todavía que hay tal cosa como un conjunto omniabarcante que le reserva a la vida un lugar propio suyo donde encontrará protección y garantías es la misma definición del optimismo. 65

El filósofo se ofrece ahora como médico de la vida aprisionada; se presenta como experto en otros lugares y ayudante durante las mudanzas. Es su misión, de acuerdo con la descripción de Sócrates en el Teeteto, obtener buenos pensamientos de circunstancias malas y, en general, aprender a vivir por encima de sus posibilidades. Como agente inmobiliario de una nueva ontología, el filosofo hace publicidad entre sus conciudadanos para que participen en dar el paso de residir en el ser. Vacunar la vida con la locura que se llama ser: gracias a esa operación el filósofo se arroga el derecho de presentarse en adelante como médico y auxiliar de mudanza de la vida cercada 66 -la filosofía se habrá convertido así en un equipo de socorristas-bajo la marca de un experto en otros lugares y en otro modo de residencia, en general, el filósofo se ofrece a la sociedad enajenada como médico especialista en enfermedades de cultura, sentido y lugar. ${ }^{67}$

Si bien el hombre no deja de pertenecer al mundo que habita, no cabe incrustarlo en él convirtiéndole en una propiedad del mundo -en mero

65 El que quiere encontrar una definición exacta de optimismo la encuentra aquí: optimista es la suposición de que hay tal totalidad abarcante.

66 SLOTERDIJK, Peter, Esferas II, Globos, Ed., cit., p. 313

67 VÁSQUEZ ROCCA, Adolfo, Peter Sloterdijk; Esferas, helada cósmica y políticas de climatización, Colección Novatores, $N^{\circ} 28$, Editorial de la Institución Alfons el Magnànim (IAM), Valencia, España, 2008. 
"ahí" del ser-; su sentido hay que buscarlo en otra parte, en un "de otro modo que ser" - y no sólo en un "ser de otro modo"-. Es así como lo humano del hombre no consiste en su pertenencia a un mundo -o en su "ex-sistencia"-, sino en un estar permanentemente abocado al "afuera" más exterior, a ése que le anuncia lo otro por excelencia: el otro hombre, el extraño inapropiable.

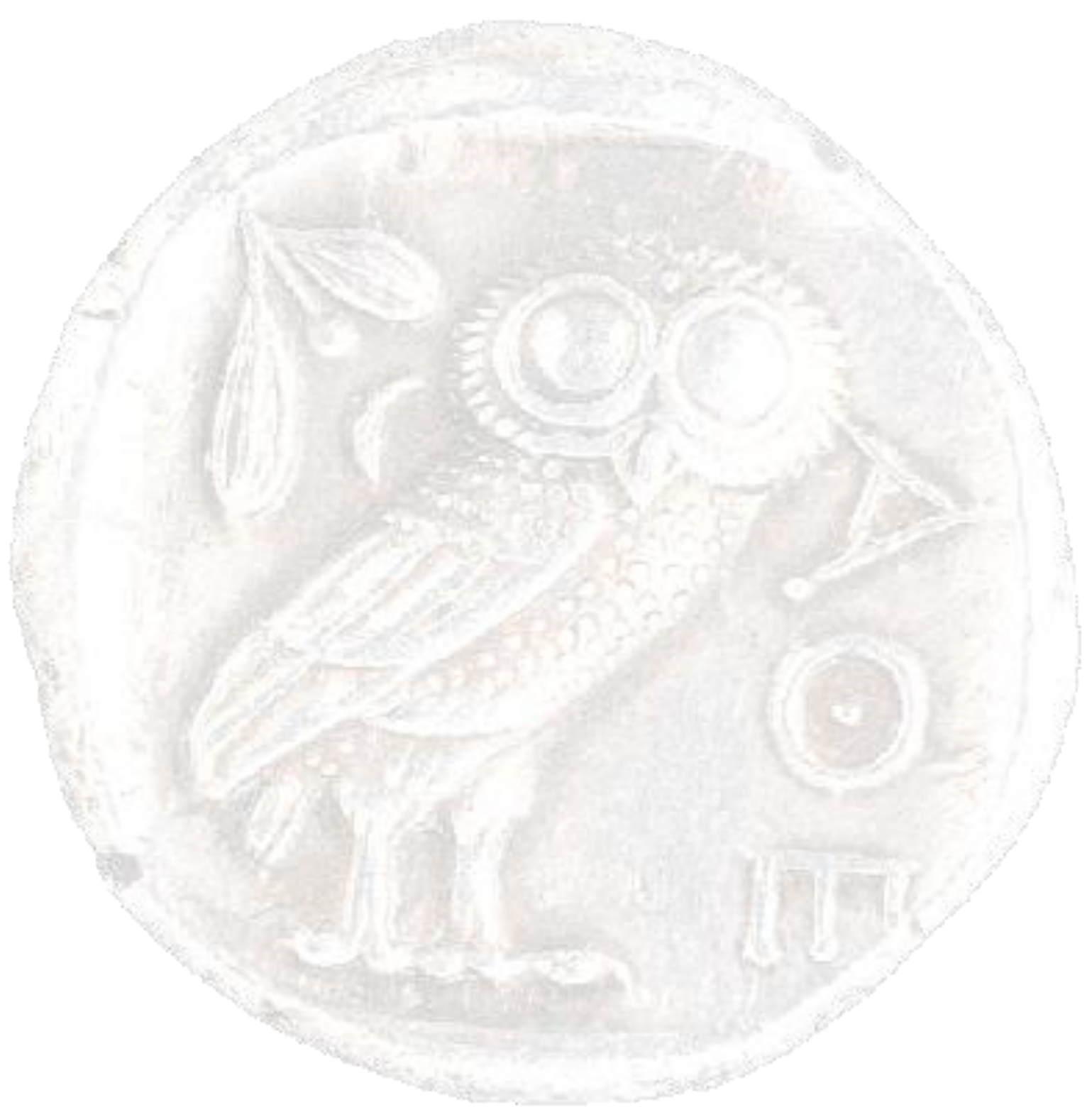




\section{7.- Sloterdijk: Heidegger y los pastores del ser. De la matriz bucólica y pastoral al "capitalismo cárnico contemporáneo".}

Mediante la técnica las generaciones en proceso de gestación tienden a elevar sus niveles de lujo y confort. La técnica sería el único elemento de traspaso que ha perdurado con una continuidad ascendente desde el surgimiento de las culturas superiores, hace cuatro o cinco mil años, hasta hoy. Sin embargo, en opinión de Sloterdijk, la labor humana de mayor relevancia, y no sólo por su factura técnica, se forjó en el período más antiguo y nebuloso de la especie, específicamente, en la milenaria vida de las hordas, momento en el que se hace posible por primera vez la generación de hombres por parte de hombres, a saber, la antropogénesis. A este gesto grupal y psicosocial de la horda, Sloterdijk lo califica como paleopolítica, esto es, "el milagro de la repetición del hombre por el hombre"68. La antropogénesis sería, entonces, el legado más antiguo de toda tradición humana, y quizás también la función primordial a la que estuvo, alguna vez, ordenado el legado completo de la técnica.

Ahora bien, el interés de Sloterdijk por el planteamiento de Heidegger se origina particularmente por las formulaciones pastorales por las que la carta sobre el humanismo es bien conocida, y eso a pesar de todos aquellos que se burlan de ellas. Ahora bien, żqué son los pastores del ser? ¿̇Quiénes son los vigilantes, y qué significa ser vecino de esa extraña abstracción (el Ser)?

Pero con esta ética de la contención ocurre algo muy particular. La comprensión heideggeriana del ser pastoral se nutre con toda seguridad de dos fuentes: de entrada, de la imagen del buen pastor cristiano, que hace lo que sea por sus ovejas, y también, por otro lado, de varias metáforas bucólico-campesinas del muchacho guardián. Ambas dimensiones tienen que ver con funciones relativamente ajenas al poderío y la técnica, habida cuenta de que el pastor de Heidegger, este punto es muy importante, no es realmente alguien con capacidad de hacer esto o lo otro; su única facultad reside en que sabe estar bien atento y se da cuenta de lo que pasa en el rebaño. Una parte de la magia de las metáforas heideggerianas radica en que identifican una aparente inacción, un vigilar en guardia, con una posibilidad suprema de ser-ahí.

¿Qué hacen, pues, los pastores heideggerianos? Están despiertos, esto es, contribuyen a que el mundo pueda ser mundo, y nada más. Aquí subyace la intuición espiritual de que lo poco es mucho, mientras que lo

68 REYES, Carlos, "La concepción político-antropológica de Peter Sloterdijk; La horda como útero social y el arte de caminar juntos", En Revista Observaciones Filosóficas $N^{\circ} 7$ / 2008. [Análisis del Texto En el mismo barco Ensayo sobre hiperpolítica. Esbozo de la Tesis de Magister desarrollada por el autor en el Instituto de Filosofía PUCV bajo la dirección del Dr. Adolfo Vásquez Rocca. <http://www.observacionesfilosoficas.net/laconcepcionpoliticaantropologica.htm> 
mucho no es casi nada si los presupuestos son falsos. No es nada mientras el polihacedor sólo siga siendo un furibundo durmiente que nunca despierta de su hipnosis activista69.

A estas indicaciones heideggerianas, procedentes de la tradición de la sabiduría y que, de nuevo, se extinguen en su seno, he añadido una observación que modifica su imagen idílica de vigilancia70. Digo así que en el claro no moran sólo pastores silenciosos y vigilantes desasidos. También hay otras figuras, no tan buenos pastores en su tarea, de los que en realidad también ha de hablarse. Se necesita acceder al conocimiento de que existen dos pastorales radicalmente diferentes: una idílica y otra inquietante, hablando en términos e historia de la cultura: una campesina y otra relativa al nomadismo ganadero. En un breve artículo titulado "Lust auf Fleisch?"71 ["¿Placer de la carne?"], Thomas Macho ha llamado la atención con agudeza sobre esta diferencia, insuficientemente percibida hasta ahora, introduciendo en su obra un nuevo paradigma filosófico en el ámbito de la historia cultural. De aquí puede aprenderse que hay un pastoreo bueno y otro malo, el que en el ámbito agrario guarda el ganado y el que cría de manera nómada el ganado. Ahora bien, mientras que Heidegger, como puede comprobarse fácilmente permanece ligado a la semántica campesina y cristiana del buen pastor, yo me permito recordar la imagen del pastoreo nómada y de los pastores malos e inquietantes, aunque seguramente de una forma extremadamente lacónica. También aquí nos las tenemos que ver con un texto subyacente que necesita ser explicitado.

Para la tradición pastoral agraria hay buenas razones para definir la conjunción de pastor y animal bajo el signo de desasimiento [Gelassenheit], por tanto es un ser ajeno a la técnica y abierto a lo presente. En todo caso, este pastor tiene que cuidar de que ningún animal se descarríe. Así se ha conservado esta imagen dentro de la tradición cristiana, incluso yendo más lejos, hasta el extremo de que el buen pastor se sacrifica por sus ovejas. Algo muy distinto ocurre en el tipo de nomadismo pastoral: éste especula con la posibilídad de establecer procesos de reproducción sobre su rebaño, y por una razón que se deja revelar con facilidad: él quiere justamente lo que en

69 SLOTERDIJK, Peter y HEINRICHS, Hans-Jürgen, EI sol y la muerte; Investigaciones dialógicas, Sirvela, Madrid, 2004, pp. 129 y sgtes.

$70 \quad$ Ibid., p. 130

$71 \mathrm{MACHO}$,Thomas, "Lust auf Fleisch?" Kulturhistorische Überlegungen zu einem ambivalenten GenUB, in: Jahrbuch 1999/2000 des Wissenschaftszentrums NordrheinWestfalen, Düsseldorf (Wissenschaftszentrum Nordrhein-Westfalen) 2000, 140-157; sowie in: Dirk Matejovski/Dietmar Kamper/Gerd-C. Weniger (Hrsg.): Mythos Neanderthal. Ursprung und Zeitenwende, Frankfurt/ Main/New York (Campus) 2001, 147-162; sowie in: Gerhard Neumann/ Alois Wierlacher/Rainer Wild (Hrsg.): Essen und Lebensqualität. Natur- und kulturhistorische Perspektiven, Frankfurt/Main/New York (Campus) 2001, 157174. 
principio no puede tener en un recinto, en concreto, tenerlo y comérselo. A la luz de su diseño civilizatorio, los pastores son carnívoros; ellos, por consiguiente, no sólo guardan sus rebaños, sino que también los vigilan y dirigen su reproducción a gran escala, de tal suerte que no cesan de conservar excedentes animales para el consumo. Ciertamente, estos pastores no portan el emblema del desasimiento como tal, sino el emblema de la producción, esto es, de la exportación animal, like it or not. Como puede comprenderse, son criadores y, eo ipso, biotécnicos en una escala muy simple, manipulan los procesos vitales con todas sus consecuencias. Si se observa esto con más detenimiento, puede reconocerse que, en el otro lado, la existencia campesina en absoluto actúa en los procesos vitales con una actitud de cuidado ajeno a la técnica, sino que también en ella las manipulaciones vitales desempeñan una función decisiva, aunque sea más bien respecto al mundo vegetal72.

Por todo ello, en el claro está en juego algo más que un mero vigilar silenciosos de lo que está ahí de suyo. La vigilancia en el claro es más que el cuidado de una apertura. Nada distinto expresó Sloterdijk en Basilea en su comentario respecto a la problemática del cuidado de lo humano en manos de los hombres. Resulta indiferente saber si aquí actúan campesinos o culturas dedicadas a la cría de ganado, lo cierto es que aquí, en ambas formas, se encuentra dada de antemano una cierta prototécnica para la intervención en procesos vitales. Criar animales y plantas significa distribuir de manera desigual oportunidades para reproducir, por tanto organizar y preferir, distinguir y subyugar según criterios establecidos en función de la utilidad humana. En este contexto se puede comprender qué enorme conflicto transcurre a través del mundo moderno, a saber: el conflicto existente entre los protectores de la vida y los exploradores de vida, expresado en tipos: el conflicto afincado entre el habitus campesino y el nómada.

El dilema ético de los hombres modernos radica en el hecho de que piensan como vegetarianos y viven como carnívoros. Ésta es la razón de que, en nosotros, la ética y la técnica nunca corran en dirección paralela. Queremos ser tan buenos como los buenos pastores, pero al mismo tiempo vivir tan bien como los malos pastores, famosos por sus fiestas violentas y su dañina vida disipada. Este dualismo tiene como efecto que todos los debates actuales sobre ética posean un cierto regusto de falsedad. Cuando habla, el hombre moderno se encuentra escindido: es un nómada con piel de cordero o un malvado pastor bajo el ropaje de una buena persona. Cuando uno se topa en la actualidad con la alabanza intelectual cada vez más popular del nómada, habría que pensar que, actuando así, se rehabilita en última instancia el modo de ser del pastoreo nómada; nadie debería creer que éste es un

72 SLOTERDIJK, Peter y HEINRICHS, Hans-Jürgen, El sol y la muerte; Investigaciones dialógicas, Siruela, Madrid, 2004, p. 131 
discurso inofensivo. A efectos de acercarnos más a este tema, podría ser de utilidad releer un libro de Jeremy Rifkin, Das Imperium der Rinder73 ["El imperio de los terneros"] (1994), en el que su posición era entonces más clara que ahora. En esta obra el monstruoso paralelismo existente entre la historia humana y la historia de la cría de ganado al por mayor es desarrollado hasta llegar a su punto culminante en el capitalismo cárnico contemporáneo.

\section{BIBLIOGRAFÍA}

1. SLOTERDIJK, Peter: (1994) En el mismo barco; ensayo sobre la hiperpolítica, Sirvela, Madrid, 2008.

2. SLOTERDIJK, Peter: Crítica de la razón cínica, (2 tomos), Ed. Sirvela, Madrid, 2003.

3. SLOTERDIJK, Peter, (2001) Sin salvación; Tras las huellas de Heidegger, Editorial, Akal, Madrid, 2011.

4. SLOTERDIJK, Peter, En el mundo interior del capital, para una teoría filosófica de la globalización, Sirvela, Madrid, 2007.

5. SLOTERDIJK, Peter, Esferas II, Globos, Editorial Siruela, Madrid, 2004

6. SLOTERDIJK, Peter, Esferas III, (1998), Sirvela, Madrid, 2004

7. CORDUA, Carla, Sloterdijk y Heidegger; La recepción filosófica, Santiago, Ediciones Universidad Diego Portales, 2008,

8. $\quad$ FARÍAS, Víctor, Heidegger et le nazisme, Verdier, París, 1987.

9. HARAWAY, Donna J., "The Biopolitics of Posmodern Bodies: Determinations of Self in Inmmune System Discourse", en: Differences, 1, $1,1989$.

10. MACHO, Thomas, "Lust auf Fleisch?" Kulturhistorische Überlegungen zU einem ambivalenten Genuß, in: Jahrbuch 1999/2000 des Wissenschaftszentrums Nordrhein-Westfalen, Düsseldorf

11. HEIDEGGER, Martin, Ser y Tiempo, Traducción de Jorge Eduardo Rivera. Trotta. Madrid, 2003. (Publicada originalmente por la Editorial Universitaria de Santiago de Chile en 1997).

12. HEIDEGGER, Martin, "La pregunta por la técnica", en Ciencia y técnica, Ed. Universitaria, Santiago, 1984

13. HORNEFFER, R., "Heidegger, guardián del ser", En Martín Heidegger. Caminos, Ricardo Guerra Tejada y Adriana Yáñez, Coordinadores, Ed. Universidad Nacional Autónoma de México, 2009

14. ROCHA DE LA TORRE, Alfredo, Martin Heidegger: la experiencia del camino, Editorial Universidad del Norte, Barranquilla, 2009

\footnotetext{
73 (Kapitel 1 aus "Das Imperium der Rinder" von Jeremy Rifkin, 1994)

RIFKIN, Jeremy, Das Imperium der Rinder. Campus-Verlag, Frankfurt / New York 1994, Frankfurt 1997, ISBN 3-596- 13606-7.

Una obra de Jeremy Rifkin, El imperio de los terneros, en donde observa el monstruoso paralelismo entre la historia humana y el de la cría de ganado al por mayor, hasta desembocar en el capitalismo cárnico actual.
} 
15. VATTIMO, Gianni, Introducción a Heidegger, Editorial Gedisa, Barcelona, 1998

16. VÁSQUEZ ROCCA, Adolfo, Peter Sloterdijk; Esferas, helada cósmica y políticas de climatización, Colección Novatores, № 28, Editorial de la Institución Alfons el Magnànim (IAM), Valencia, España, 2008.

17. RIVERA, Jorge Eduardo, Heidegger y Zubiri, Ed. Universitaria, Chile, 2001

18. HEIDEGGER, Martin (1997), "EEl origen de la obra de arte», en Caminos de bosque, trad. H. Cortés y A. Leyte, Madrid: Alianza.

19. HEIDEGGER, Martin, Introducción a la metafísica [Einführung in die Metaphysik], Editorial: Nova, Buenos Aires, 1980

20. TUGENDHADT, Ernst (2002), «Dificultades en el análisis heideggeriano del mundo circundanten, en Problemas, Barcelona: Gedisa.

21. HEIDEGGER, Martin (1998) [ed.orig. 1927], Ser y tiempo, trad. J. Rivera, Santiago de Chile: Editorial Universitaria.

22. HEIDEGGER, Martin (2000), Ontología. Hermenéutica de la facticidad, trad. J. Aspiunza, Madrid: Alianza.

23. HEIDEGGER, Martin, "El Rectorado", en, Escritos sobre la Universidad alemana, Madrid: Tecnos, 1989 